\title{
Black mould of post-harvest tomato (Solanum lycopersicum) caused by Cladosporium cladosporioides in Australia
}

\author{
Minxiao Ma ${ }^{1} \cdot$ Dilani D. de Silva $^{1,2} \cdot$ Paul W. J. Taylor $^{1}$ (D) \\ Received: 21 April 2020 / Accepted: 19 June 2020 / Published online: 25 June 2020 \\ (C) Australasian Plant Pathology Society Inc. 2020
}

\begin{abstract}
Tomato (Solanum lycopersicum) is an important global vegetable crop for both the fresh and processed vegetable industries. Tomatoes from a cold storage refrigerator $\left(4{ }^{\circ} \mathrm{C}\right)$ in Melbourne, Australia exhibiting symptoms of black to dark-olive, sunken lesions were found to be infected by Cladosporium cladosporioides based on morphological and molecular identification. Pathogenicity tests confirmed that $C$. cladosporioides was the cause of the black mould on tomato fruits. This is the first report of $C$. cladosporioides causing black mould on harvested tomato fruits in Australia.
\end{abstract}

Keywords Tomato $\cdot$ Cladosporium $\cdot$ Post-harvest pathology

Tomato (Solanum lycopersicum) is one of the most widely cultivated crops in the world, which is used in both the fresh and processing vegetable industries (Dam et al. 2005). In Australia, tomato is of large economic importance being the second largest vegetable industry in production (FAOSTAT 2019).

In July 2018, all Truss Tomato fruits purchased from a supermarket and stored for ten days in a domestic cold storage refrigerator $\left(4^{\circ} \mathrm{C}\right)$ in Melbourne, Australia developed symptoms similar to tomato black mould reported in USA (Bartz 1972; Jones et al. 2014). Black to dark-olive, flattened or sunken lesions (3 to $11 \mathrm{~mm}$ in diameter) surrounded by water-soaked tissue were visible on the skin of red ripe infected tomato fruit (Fig. 1a), making the infected fruit unsuitable for consumption. No symptoms have ever been seen on previous stored tomatoes in the same facility.

To identify the pathogen causing the lesions, tissue from the margins of the lesions of two tomato fruits were sterilized

Paul W. J. Taylor

paulwjt@unimelb.edu.au

1 Faculty of Veterinary and Agricultural Sciences, The University of Melbourne, Parkville, VIC 3010, Australia

2 Present address: Department of Jobs, Precincts and Regions, Agriculture Victoria Research, AgriBio, La Trobe University, Bundoora, VIC 3083, Australia with $80 \%$ ethanol, then three tissue samples $\left(0.5 \mathrm{~cm}^{2}\right)$ were cultured on water agar. Hyphae that grew from the tissue were then subcultured on potato dextrose agar (PDA) and incubated at $25{ }^{\circ} \mathrm{C}$. After seven days, powdery, velvet, olive-green to olive-brown colonies with white, aerial and feathery mycelium developed (Fig. 1b). These colony types share similar characteristics with species of Cladosporium spp. (de Hoog et al. 2000). To obtain pure cultures, the isolates were single-spored and incubated on PDA at $20^{\circ} \mathrm{C}$ in dark for ten days. From a total of six single-spored isolates, two representative isolates were deposited at the National Collection of Fungi, Bundoora Herbarium (VPRI; Table 1) and also stored in the University of Melbourne (UM) collection at $-80{ }^{\circ} \mathrm{C}$. Hyphae, conidia, and conidiophores were mounted on glass microscope slides containing lactic acid. Spore shape and size were determined using a Leica DM6000 LED compound microscope and Leica LAS X software (Leica, Aust).

The hyphae of the isolates were sparse, septate, sometimes branched and pale brown (Fig. 1c). The width of the hyphae of the isolates was 2-6 $-\mathrm{m}$ ( $3 \mu \mathrm{m}$ in average). The conidiophores were solitary, macronematous and arose at the terminals of the hyphae, usually with a straight, filiform, cylindrical shape with brown colour, often unbranched with slightly thickened walls (Fig. 1d). The size of the conidiophores were (41-)53$72(-93) \times(2-) 3-4(-5) \mu \mathrm{m}($ av. $65 \times 4)$. The numerous singlecelled brown conidia varied largely in shape from round, ovoid, obovoid to lemon-shaped with notches on the conidia attached to the conidiophores (Fig. 1e). They were usually in 
Fig. 1 Lesions caused by Cladosporium cladosporioides on fruit of S. lycopersicum (a); colony morphology of 14-day-old C. cladosporioides on PDA (b); hyphae (c); conidia (d); conidiophore (e); symptoms on S. lycopersicum fruits inoculated with $C$. cladosporioides (f). Scale bars: c, d, e: $20 \mu \mathrm{M}$
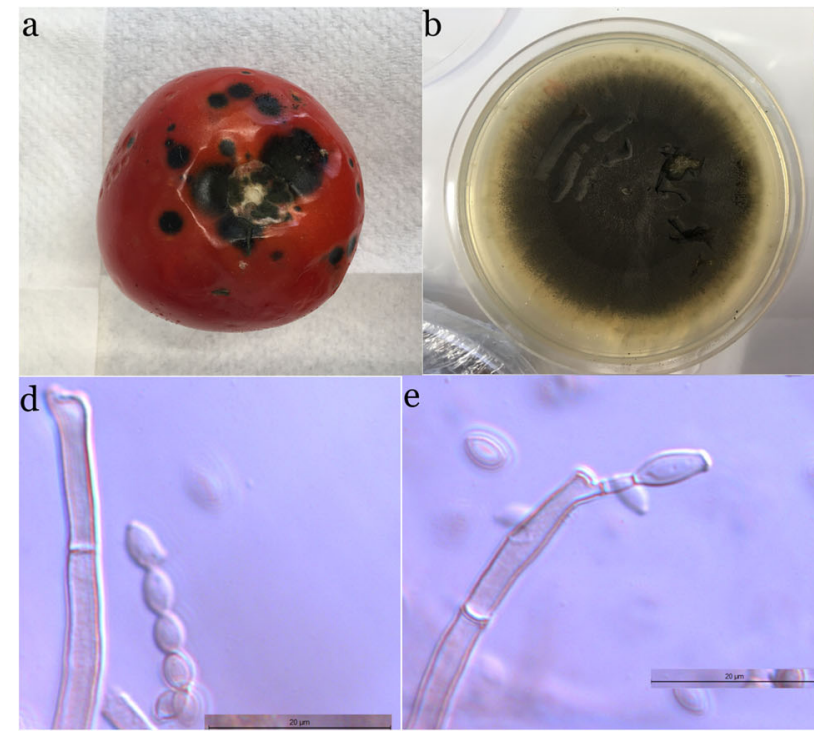

e

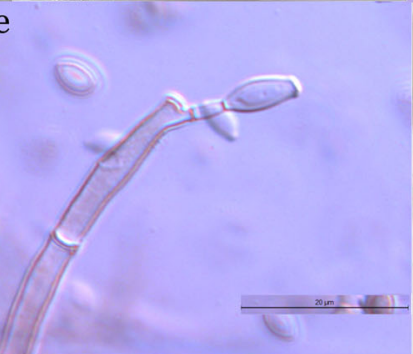

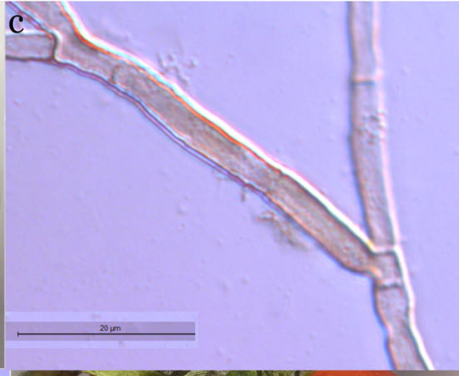

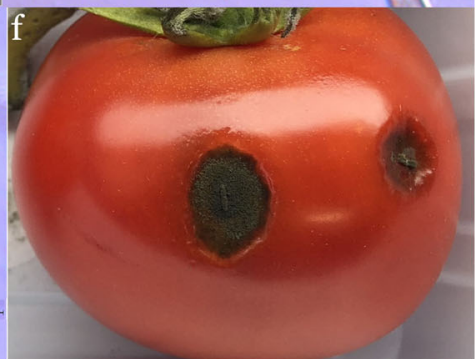

long chains stretching in all directions made up of several conidia, which were septate to each other with the terminal conidium being relatively small. The size of the conidia of the isolates were $(2-) 3-5(-9) \times(2-) 3(-5) \mu \mathrm{m}($ av. $4 \times 3$ ). The morphological analysis suggested that the colour, shape and size of conidia and hyphae of the isolates matched the characteristics of the corresponding structures of the type isolate of C. cladosporioides described by Bensch et al. (2010). However, the conidiophores were slightly shorter than the average size (15-)45-210(-360) $\times(2-) 3-4(-5) \mu \mathrm{m}$ described by Bensch et al. (2010).

Genomic DNA of the two representative isolates VPRI $43684=\mathrm{UMCld} 01$ and VPRI $43685=\mathrm{UMCld} 02$ were ex tracted from 14-day-old fungal colonies grown on PDA following the protocol of De Silva et al. (2017). Then the internal transcribed spacer region of rDNA (ITS), the translation elongation factor $1-\alpha$ (TEF- $1 \alpha$ ) and the actin (ACT) genes were amplified with a Bio-Rad T100 ${ }^{\mathrm{TM}}$ Thermal Cycler following the protocols described by Bensch et al. (2012). The primer pairs were ITS1/ITS4 for ITS (Meneses et al. 2018), EF1-786F/EF1-986R (O’Donnell et al. 1998) for TEF- $1 \alpha$ and ACT512F/ACT783R for ACT (Carbone and Kohn 1999). The polymerase chain reaction (PCR) was performed in a 2720 Thermal Cycler (Applied

Table 1 GenBank accession numbers for the ITS, ACT and TEF gene sequences for VPRI 43684 and VPRI 43685

\begin{tabular}{llll}
\hline Isolate & ITS & ACT & TEF \\
\hline VPRI 43684 & MT452651 & MT459444 & MT459446 \\
VPRI 43685 & MT452652 & MT459445 & MT459447 \\
\hline
\end{tabular}

Biosystems) with a $25 \mu \mathrm{L}$ reaction mixture. The mixture comprised $1 \mathrm{x}$ PCR buffer, $0.2 \mathrm{mM}$ dNTP, $0.4 \mu \mathrm{M}$ of each primer, $2 \mathrm{mM} \mathrm{MgCl} 2,1 \mathrm{U}$ Taq DNA polymerase (MangoTaq DNA polymerase; Bioline) and $20 \mathrm{ng}$ template DNA with components adjusted as required (De Silva et al. 2017).

The products of PCR were purified and sequenced by the Australian Genome Research Facility (AGRF, Melbourne). The acquired sequences were then aligned with MEGA-X software (Kumar et al. 2018) and underwent a BLAST search within the GenBank sequence database of National Center for Biotechnology Information (NCBI). The result of the BLAST search showed that the gene sequences of the two selected isolates (Table 1) shared high $(>90 \%)$ similarity with those of several strains of Cladosporium cladosporioides (not shown). Then, the sequences were used to construct a multi-gene maximum likelihood tree with the gene sequences retrieved from extype culture of $C$. cladosporioides, ten type species of Cladosporium species closely related to C. cladosporioides, two voucher cultures of $C$. cladosporioides, and Cercospora beticola (Bensch et al. 2012). Each gene was aligned and concatenated for a combined phylogenetic analysis using MEGA-X with 1000 bootstrap replications, Tamura-Nei model as substitution model, uniform rates, maximum parsimony and Nearest-Neighbor-Interchange for inference. The phylogram (Fig. 2) showed that the sequences obtained from two isolates formed a clade with $100 \%$ bootstrap value with sequences from three reference isolates of $C$. cladosporioides and a sub clade with the sequence of the ex-type species of C. cladosporioides with $65 \%$ bootstrap value. According to the phylogenetic tree, the isolates VPRI 43684 and VPRI 43685 were placed in a monophyletic clade comprising 
Fig. 2 Maximum likelihood phylogenetic tree of Cladosporium cladosporioides generated from the combined dataset of ITS, ACT and tefl gene sequences. Bootstrap values from 1000 replicates are shown at nodes. The bar indicates the number of substitutions per position. * indicates the ex-type and type isolates

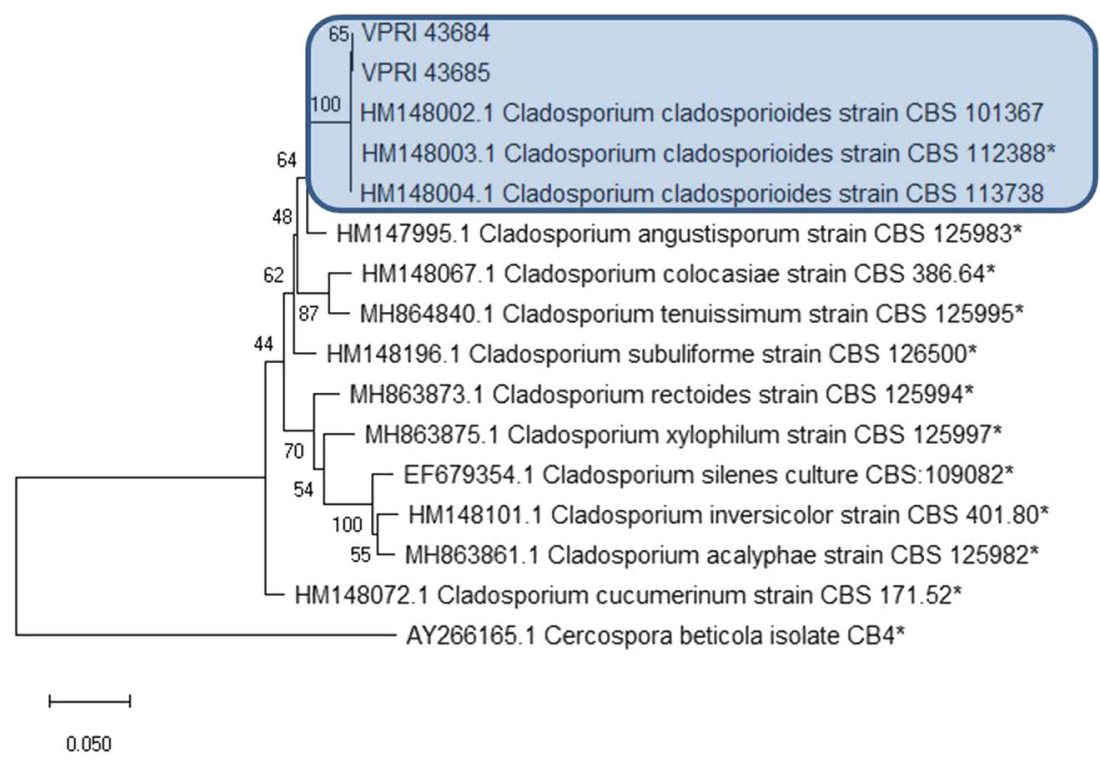

reference isolates of $C$. cladosporioides, forming a separate clade distinct from other Cladosporium species. Therefore, the isolates were confirmed as $C$. cladosporioides.

The pathogenicity of the isolates was determined on both red Truss Tomato fruits and the first fully expanded leaf of tomato cultivar H3402. Fruit surfaces were sterilised with $80 \%$ ethanol and detached leaves were sterilised in $1 \%$ ai of sodium hypochlorite for one minute, then rinsed in three changes of sterile distilled water. Conidial suspensions were prepared as described by De Silva et al. (2017). Fruits were inoculated with conidial suspension of $10^{6}$ conidia per $\mathrm{mL}$ of isolate VPRI 43684 by both wound and non-wound methods. For the wound method, the cuticle and epidermis of the fruit were wounded by pricking with a sterilised needle then $10 \mu \mathrm{l}$ of spore suspension was placed over the wound. For the non-wound method $10 \mu \mathrm{l}$ of spore suspension was placed on the fruit surface. Control fruits were treated with $10 \mu \mathrm{l}$ of sterile water. For the leaf inoculation $10 \mu \mathrm{l}$ of spore suspension was placed directly onto the upper surface of the detached leaves. Inoculated fruits and leaves were then incubated in closed opaque plastic boxes at $25^{\circ} \mathrm{C}$. After 12 days, black, sunken lesions covered with olive-green mycelia and conidiophores (Fig. 1f) were observed on both wound and non-wound sites on fruits inoculated with spore suspension. No symptoms were observed on the inoculated leaves.

The inoculation test showed that this pathogen can infect both wounded and non-wounded post-harvest tomato fruits. The lack of infection on leaves indicates that C. cladosporioides is likely to be a post-harvest pathogen that does not infect plants during growth. This is the first report of C. cladosporioides causing black mould on postharvest tomato fruit in Australia.

Acknowledgements This work was financially supported by the University of Melbourne. We like to thank Dr. Azin Moslemi, Sophia Callaghan and Weixia Wang for technical assistance.

\section{Compliance with ethical standards}

This article follows the experimental guidelines of Australia.

Conflict of interest The authors declare that they have no conflict of interest.

\section{References}

Bartz JA (1972) Studies on the causal agent of black fungal lesions on stored tomato fruit. Proc Fla St Hort Soc 84:117-119

Bensch K, Groenewald Z, Dijksterhui J et al (2010) Species and ecological diversity within the Cladosporium cladosporioides complex (Davidiellaceae, Capnodiales). Stud Mycol 67:1-94

Bensch K, Braun U, Groenewald JZ, Crous PW (2012) The genus Cladosporium. Stud Mycol 72:1-401

Carbone I, Kohn LM (1999) A method for designing primer sets for speciation studies in filamentous ascomycetes. Mycologia 91:553556

Dam BV, Goffau MD, de Jeude L, Naika S (2005) Cultivation of tomato: Production, processing and marketing. <https://cgspace.cgiar.org/ bitstream/handle/10568/52975/1296_PDF.pdf?sequence=4>

de Hoog GS, Guarro J, Gené J et al (2000) Atlas of clinical fungi $3^{\text {rd }}$ eedition. Utrecht / Reus

De Silva DD, Ades PK, Crous PW, Taylor PWJ (2017) Colletotrichum species associated with chili anthracnose in Australia. Plant Pathol 66:254-267

FAOSTAT (2019) < http://www.fao.org/faostat/en/\#data/QC> 
Jones JB, Zitter TA, Momol TM, Miller SA eds (2014) Compendium of tomato diseases and pests, $2^{\text {nd }}$ edn. APS Press, Minnesota, USA

Kumar S, Stecher G, Li M, Knyaz C, Tamura K (2018) MEGA X: molecular evolutionary genetics analysis across computing platforms. Mol Biol Evol 35:1547-1549

Meneses PR, Dorneles KDR, Bellé C, Moreira-Nuñez VL, Gonçalves V, Farias CRJ (2018) First report of Cladosporium cladosporioides causing leaf spot on Alstroemeria aurea in Brazil. Plant Dis 102: 1849

O’Donnell K, Kistler HC, Cigelni E, Ploetz RC (1998) Multiple evolutionary origins of the fungus causing Panama disease of banana: concordant evidence from nuclear and mitochondrial gene genealogies. P Natl Acad Sci USA 95:2044-2049 